\title{
Reactors for Catalytic Methanation in the Conversion of Biomass to Synthetic Natural Gas (SNG)
}

\author{
Tilman J. Schildhauer ${ }^{\star}$ and Serge M. A. Biollaz
}

\begin{abstract}
Production of Synthetic Natural Gas (SNG) from biomass is an important step to decouple the use of bioenergy from the biomass production with respect to both time and place. While anaerobic digestion of wet biomass is a state-of-the art process, wood gasification to producer gas followed by gas cleaning and methanation has only just entered the demonstration scale. Power-to-Gas applications using biogas from biomass fermentation or producer gas from wood gasification as carbon oxide source are under development. Due to the importance of the (catalytic) methanation step in the production of SNG from dry biomass or within Power-to-Gas applications, the specific challenges of this step and the developed reactor types are discussed in this review.
\end{abstract}

Keywords: Catalytic fixed bed reactor - Fluidized bed $\cdot$ Methanation · Power-to-Gas · SNG

\section{Introduction}

Synthetic Natural Gas (SNG) is a widely accepted and versatile energy carrier that can be easily distributed through the existing natural gas grid and be efficiently used, e.g. for mobility in compressed natural gas cars. There are several pathways to produce SNG from biomass, see Fig. 1. The most common process used currently is anaerobic digestion of wet biomasses from agriculture and of organic wastes from households and gardening, e.g. Kompogas ${ }^{\circledR}$. It delivers a mixture of mainly methane $\left(\mathrm{CH}_{4}\right)$ and carbon dioxide $\left(\mathrm{CO}_{2}\right)$. This so-called biogas can be regarded as raw SNG which has to be further upgraded by $\mathrm{CO}_{2}$ removal and drying before injection into the natural gas grid to fulfil the quality specifications with respect to density and heating value.
${ }^{\star}$ Correspondence: Dr. T. J. Schildhauer Paul Scherrer Institute $\mathrm{CH}-5232$ Villigen PSI

E-mail: tilman.schildhauer@psi.ch
Raw SNG can also be produced from biomass by gasification. Classical gasification of dry biomass, especially wood, is combined with gas cleaning for the removal of catalyst poisons and subsequent methanation. ${ }^{[1]}$ Hydrothermal gasification/ methanation of wet biomass allows the conversion of algae sludge or manure. ${ }^{[2]}$ Again, gas up-grading is necessary before injection into the natural gas grid. Recently a first $20 \mathrm{MW}_{\mathrm{SNG}}$ Wood-to-SNG plant was commissioned in Gothenburg/Sweden..$^{[3]}$

Due to the existing subsidization of electricity production from renewable sources, the upgrading of biogas to $\mathrm{SNG}$ competes with its direct combustion in gas engines for decentralised combined heat and power production (CHP). The same holds for producer gas from biomass gasification. In most wood gasification installations, e.g. in Stans/Switzerland or in Güssing and Oberwart/Austria, the gas is converted to electricity (with 25-28\% efficiency) and heat. Even higher electric efficiency would be possible by applying high-temperature fuel cells ${ }^{[4]}$ which, however, ask for a more thorough (hot) gas cleaning. ${ }^{[5]}$ State-of-the-art technology to produce electricity from wood is combustion of wood followed by steam turbine. Small-scale systems, i.e. from $300 \mathrm{~kW}_{\mathrm{el}}$ to $1500 \mathrm{~kW}_{\text {el }}$ have an efficiency of $15 \%$; larger installations like the wood CHP in Aubrugg $\left(10 \mathrm{MW}_{\mathrm{el}}\right)$ reach $25 \%$ electrical efficiency.

In so-called Power-to-Gas applications, the amount of SNG from biomass or biomass-derived raw SNG can be further increased by addition of hydrogen $\left(\mathrm{H}_{2}\right.$, produced by electrolysis from excess electricity). This allows also the (seasonal) storage of excess electricity from stochastic sources such as wind turbines and photovoltaics or its use as SNG in the mobility sector. In a methanation step, the hydrogen can react with $\mathrm{CO}_{2}$ in the raw SNG, until a mixture of mainly methane and (condensable) water is reached.

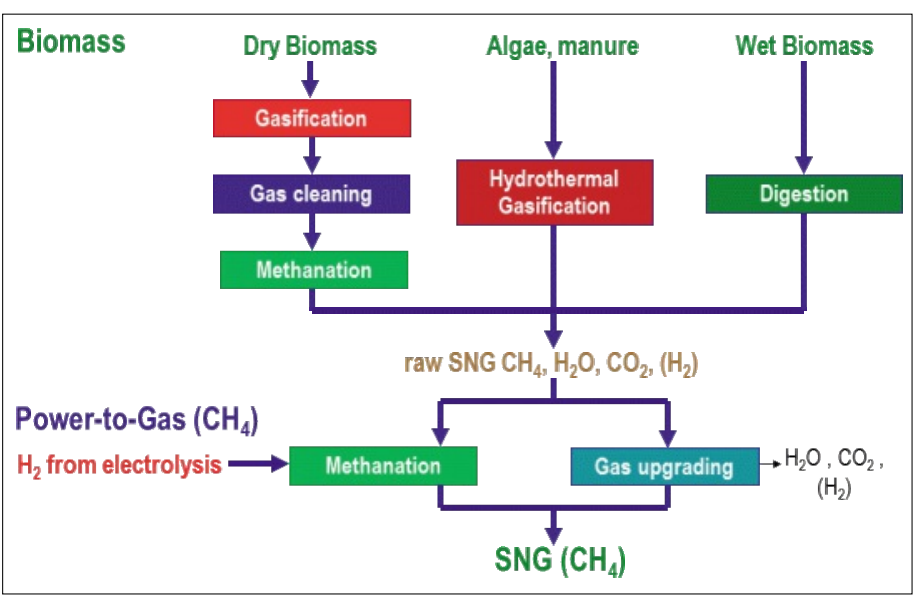

Fig. 1. Different pathways from biomass to Synthetic Natural Gas (SNG). 
Due to the importance of the (catalytic) methanation step in the production of SNG from dry biomass or within Power-to-Gas applications, the specific challenges of this step and the developed reactor types are discussed in this contribution.

\section{Requirements for Catalytic Methanation Reactors}

Methanation is the synthesis step in the production of SNG. In order to optimize the chemical efficiency, the goal is to convert as many carbon atoms to fuel as possible. Biogas contains carbon mainly as $\mathrm{CH}_{4}$ and $\mathrm{CO}_{2}$; depending on the gasification process, producer gas from wood gasification however comprises mainly $\mathrm{CO}, \mathrm{CO}_{2}$ (usually above $20 \mathrm{~mol} \%$ ) and $\mathrm{CH}_{4}(1-10$ mol\%), but also $\mathrm{C}_{2}$ species (up to $4 \mathrm{~mol} \%$ ) such as ethane, ethene and ethyne. Further, traces of aromatic compounds such as benzene, toluene and naphthalene are present. Due to the specification with respect to heating value and density for injection of SNG into the natural gas grid, the content of methane (and ethane) should be maximized; $\mathrm{CO}, \mathrm{CO}_{2}$, hydrogen and unsaturated hydrocarbons have to be converted by methanation or removed either in the gas cleaning and conditioning step upstream or in the gas upgrading downstream. Therefore, the following reactions take place in methanation reactors: $\mathrm{CO}$ - and $\mathrm{CO}_{2}$-methanation, water gas shift reaction (WGS) and reverse WGS, hydrogenation of unsaturated hydrocarbons, e.g. ethene to ethane, and hydrogenolysis of larger hydrocarbons to methane. As side reactions, the molecules involved can form a number of different carbon depositions which may deactivate the catalyst. The contribution of Kambolis et al. ${ }^{[6]}$ in this issue discusses all these reactions in more detail.

There are three main challenges for methanation reactors:

- The feed gas may contain catalyst poisons such as sulphur species;

- The carbon deposition, which is even favoured at high temperatures, i.e. above $500{ }^{\circ} \mathrm{C}$;

- Most of the reactions are strongly exothermic.

\subsection{Sulphur Species}

Nickel-based catalysts are usually applied for methanation. Therefore, the sulphur content has to be below $1 \mathrm{ppm}$ to reach a catalyst lifetime of at least one year, which is considered economically necessary. ${ }^{[7]}$ While there are a number of adsorption-based technologies to remove the most common sulphur species hydrogen sulphide $\left(\mathrm{H}_{2} \mathrm{~S}\right)$, raw gas from low temperature gasification of dry biomass contains a large number of aromatic sulphur species such as thiophenes, benzo-thiophenes and dibenzo-thiophenes. ${ }^{[8]}$ Due to their thermal stability, they have to be either removed by cold scrubbers or to be converted to easily removable $\mathrm{H}_{2} \mathrm{~S}$ in catalytic steps. [9] For the latter, a number of different concepts is followed, e.g. hydrodesulphurization ${ }^{[10]}$ or reforming with zirconia-based ${ }^{[11]}$ or noble metal-based catalysts. ${ }^{[12]}$ Further, chemical looping reforming steps have been developed. ${ }^{[13]}$ So far, no clear candidate for best practice has been identified.

\subsection{Carbon Deposition}

Carbon monoxide is produced in biomass gasification or can be formed from $\mathrm{CO}_{2}$ and hydrogen by reverse water gas shift reaction. $\mathrm{CO}$ strongly adsorbs on nickel catalyst and can form single carbon atoms on the catalyst surface. ${ }^{[14]}$ If it is not hydrogenated fast enough, it either can dissolve in the nickel, which leads to formation of nickel carbides or carbon nanofibres or it can polymerise on the nickel catalyst, which can cause blockage of active sites. ${ }^{[15,16]}$ Therefore, already a too low local hydrogen to carbon ratio can slowly lead to catalyst deactivation.

Hydrocarbons can also form carbon atoms on the catalyst surface[17] whereby especially the unsaturated species such as ethene have very high rate of carbon deposition. As a result, ethene and ethyne lead to fast and strong catalyst deactivation when the catalyst is applied as a fixed bed of catalyst particles. ${ }^{[18]}$ From many investigations, e.g. ref. [15], it is known that the carbon deposition rate increases faster with increasing temperature than the carbon removal rate due to hydrogenolysis or steam reforming.

\subsection{Exothermicity of the Methanation Reactions}

The strong exothermic character of the methanation leads to a significant tem- perature increase in catalytic reactors, if no or insufficient heat removal is applied. Depending on the composition of the feed gas mixture, thermodynamic equilibrium will limit further conversion. Therefore, the temperature rise leads to hot spots of $550{ }^{\circ} \mathrm{C}$ to $750{ }^{\circ} \mathrm{C}$. Such high temperatures may damage the catalyst through sintering. Further, as mentioned above, the high temperatures favour carbon-depositing side reactions. The thermodynamic limitation of the exothermic methanation reaction necessitates an efficient cooling of the reactor or the application of several reactors in series with intermittent cooling to allow for nearly complete conversion of the carbon oxides.

\section{Industrial Methanation Reactors}

So far, a number of different methanation reactor concepts has been developed which can cope with the challenges and requirements described in the previous section. These concepts and their application in the conversion route from biomass to SNG will be described in the next few sections.

\subsection{Series of Adiabatic Fixed-bed Reactors (GoBiGas/TREMP ${ }^{\circledR}$ ECN)}

In the Gothenburg Biogas Project, wood with a thermal input of $32 \mathrm{MW}_{\text {th }}$ is gasified in an allothermal dual fluidised-bed gasifier (DFB) and converted in several steps to around $20 \mathrm{MW}_{\mathrm{SNG}}$ of Synthetic Natural Gas (Fig. 2). The plant was commissioned at the end of 2014

TheDFB gasifier (e.g. the Fast Internally Circulating Fluidised Bed gasifier, FICFB, as built in Gothenburg, Güssing, Oberwart or Senden ${ }^{[19]}$ ) is today the most widely applied and reliable wood gasifier and delivers a hydrogen-rich producer gas which already contains a high fraction of methane

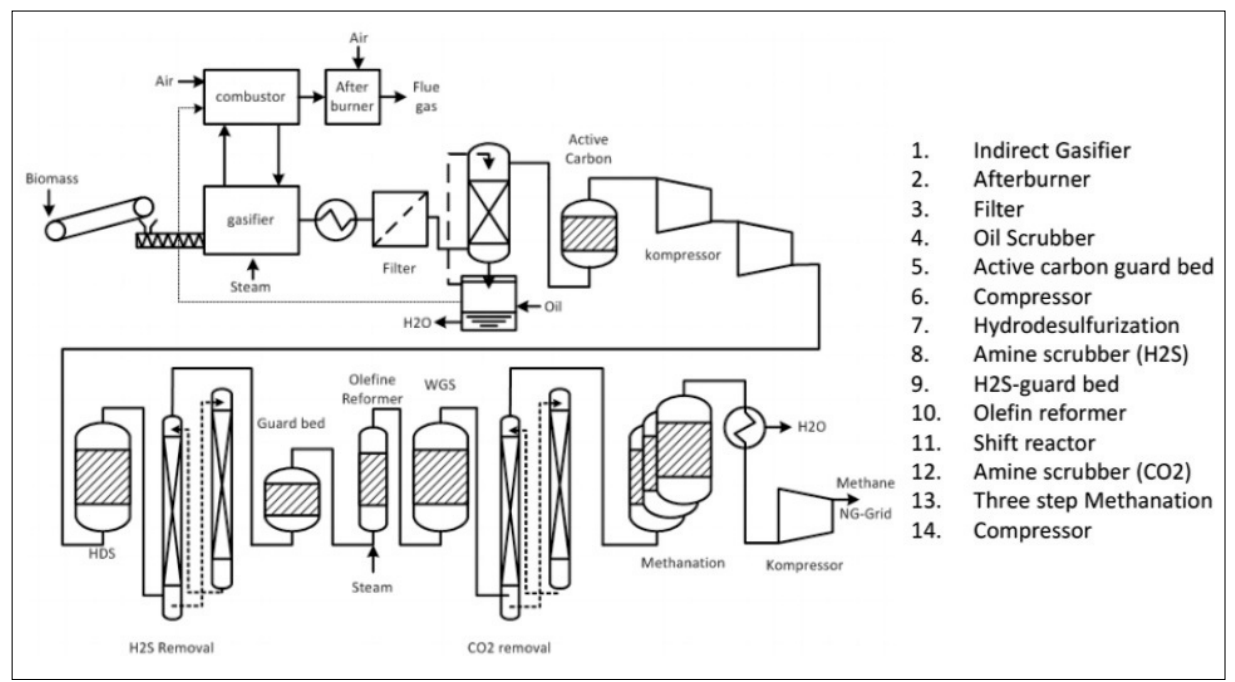

Fig. 2. Simplified scheme of GoBiGas plant (without heat exchangers), from ref. [20]. 
(around 10\%). The high methane content is very favourable for the overall process chain efficiency, but is connected to a relative high content of unsaturated hydrocarbons (especially ethene $\mathrm{C}_{2} \mathrm{H}_{4}$ ); further, several aromatic compounds including thiophenes are present in the producer gas. For methanation, a series of several adiabatic fixed bed reactors have been chosen, which are delivered by Haldor Topsoe A/S based on their successful TREMP ${ }^{\circledR}$ process to convert coal gasification-derived producer gas at large scale to SNG.

As these adiabatic fixed-bed reactors are very prone to carbon deposition due to several percent of ethene in the gas, the ethene has to be converted upstream. This is realised by hydrogenation of major parts of ethene to ethane in the hydrodesulfurisation step (HDS) and subsequent conversion of the ethane and residual ethene in the so-called olefin reformer. The HDS step also allows for conversion of thiophenes species to $\mathrm{H}_{2} \mathrm{~S}$ that can be easily separated downstream by the adsorbers. While so far only little is known about the performance of the complete process chain, it can be stated that this process is relatively complex as the temperature level is changed several times: while HDS, olefin reformer and methanation are operated at temperature higher than $300{ }^{\circ} \mathrm{C}$, the $\mathrm{H}_{2} \mathrm{~S}$ removal and the $\mathrm{CO}_{2}$ removal are operated at low temperatures. Moreover, further heat exchangers are necessary between the adiabatic methanation reactors. Due to the exothermic reaction $(-206 \mathrm{~kJ} / \mathrm{mol})$, the reaction temperature rises strongly and the conversion is limited by thermodynamic equilibrium, as mentioned above. Therefore, the gas has to be cooled down before the next reactor entrance.

A similar process chain has been operated in pilot scale by ECN (Energy Research Center of the Netherlands); ${ }^{[21]}$ the main differences are i) that they use their proprietary Milena-Gasification and their proprietary OLGA-scrubber system for tar removal, ii) that the $\mathrm{H}_{2} \mathrm{~S}$ removal is realised by hot temperature adsorbers to avoid strong cooling down below the dew point of water, and iii) that the $\mathrm{CO}_{2}$ removal is conducted after the methanation which dampens the temperature increase in the methanation. Still, heat exchangers between the HDS and the methanation section as well as between the methanation reactors are necessary, although most probably with a lower surface area than in the GoBiGas plant.

\subsection{Cooled Fixed-bed Reactors for Power-to-Gas Application (etogas $\mathrm{GmbH}$, Werlte)}

Based on the successful reactor development of ZSW (Zentrum für Solare Wasserstofferzeugung) in Stuttgart, the company Solarfuel GmbH (today etogas $\mathrm{GmbH}$ ) developed a process for the conversion of $\mathrm{CO}_{2}$ with hydrogen to methane. This process is one of the core technologies of so-called Power-to-Gas applications where excess electricity, especially from volatile renewable sources such as photovoltaics and wind, is not curtailed but used to produce hydrogen by electrolysis. The hydrogen can be used directly, either for mobility or with some storage for re-electrification, e.g. to cover peaks in the electricity demand. If the necessary duration or volume of the storage exceeds the capacities for hydrogen storage, conversion into methane and injection into the existing natural gas grid is an important option which then needs a source of carbon oxide. Raw SNG from anaerobic digestion of wet biomass or producer gas from gasification of dry biomass are the most suited carbon oxide sources in the range from 1 MW to several ten MW.

The reactor concept of $\mathrm{ZSW}$ is based on a multi-tubular fixed bed reactor where the nickel-based catalyst is filled into tubes of small diameter which are cooled by molten salt or other cooling media. As shown by recent modelling/simulation studies, ${ }^{[22,23]}$ the cooling does not help to avoid a significant hotspot of above $650{ }^{\circ} \mathrm{C}$ in case of stoichiometric $\mathrm{CO}_{2}$-methanation, because the heat released by the reaction can only be removed locally, which limits the available heat transfer area. Therefore, the catalyst has to withstand such high reaction temperatures without rapid catalyst sintering. Alternatively dilution with methane, e.g. by direct methanation of biogas from anaerobic digestion, or with recycled product gas, can dampen the temperature increase. Due to hot spot formation, the presence of carbon-depositing compounds should be minimised. Still, the reactor cooling helps to decrease the temperature and, in consequence, to increase the conversion of the thermodynamically limited, exothermic methanation (Fig. 3). In consequence, full conversion is possible by using only

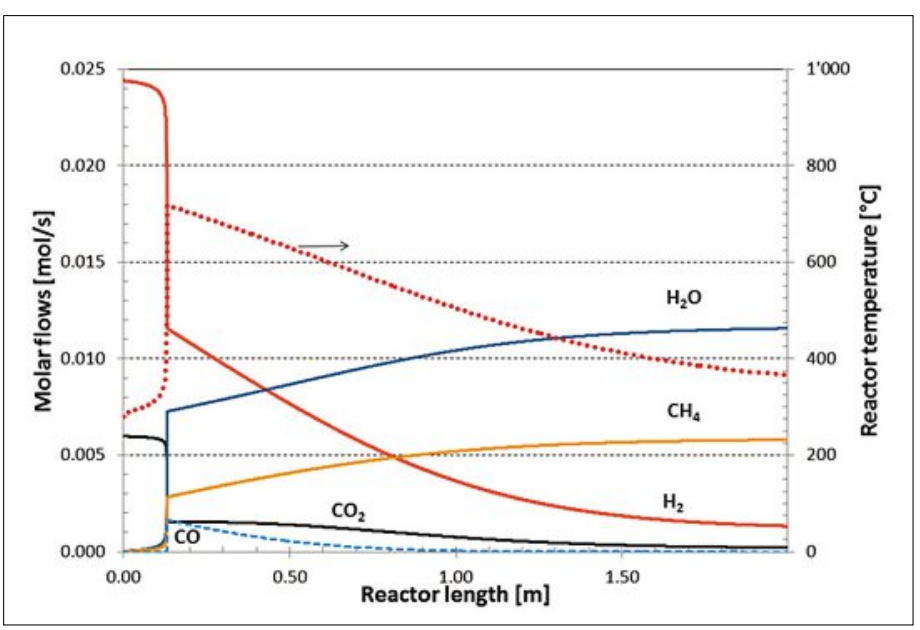

two reactors with intermediate condensation of water, but the reactor size depends strongly on the heat removal performance. Compared to the GoBiGas methanation section, a lower number of units, but more complex and therefore more costly equipment (reactors with integrated heat exchangers and molten salt cooling) has to be used.

The technology was successfully scaled-up from a $25 \mathrm{~kW}$ container-based system for field tests, e.g. with direct biogas methanation, to a $250 \mathrm{~kW}$ pilot scale plant in Stuttgart. In Werlte/Germany, a first commercial size plant was built with financial support of Audi AG that converts $6 \mathrm{MW}_{\mathrm{el}}$ from wind turbines to hydrogen using the $\mathrm{CO}_{2}$ from a biogas plant. The $\mathrm{CO}_{2}$ is separated from the biogas by means of an already existing amine scrubber; the heat of the methanation can be used for the regeneration of the amine washing agent. The efficiency of the Power-to-Gas process depends strongly on the efficiency of the electrolysis (60-75\% depending on the electrolysis type and the dynamic partload pattern); the methanation efficiency is determined by thermodynamics and reaches $75-80 \%$ depending on the specific gas composition. Overall, efficiency from electricity to methane of $45-56 \%$ seems realistic.

\subsection{Fluidised-bed Methanation (Paul Scherrer Institut)}

Research at Paul Scherrer Institut in Switzerland focuses on the development of a process from wood to SNG applying low-temperature gasification as a first step because low temperature gasification leads to high methane contents in the producer gas. This in turn significantly increases the overall process chain efficiency. As mentioned above, the high methane content in gasification producer gas implies also a significant amount of unsaturated species, especially olefins, which cause severe carbon deposition in state-of-the art fixed bed methanation reactors. To simplify the gas
Fig. 3. Simulation of $\mathrm{CO}_{2}$ methanation for Power-to-Gas application: results for one tube (diameter 25 $\mathrm{mm}$ ) of a multi-tubular cooled fixed bed reactor with slightly over-stoichiometric (4.1 to 1) mixture of $\mathrm{H}_{2}$ and $\mathrm{CO}_{2}$ at 10 bar with inlet temperature $280^{\circ} \mathrm{C}$ and cooling temperature $340{ }^{\circ} \mathrm{C}$ : molar flows (full and dashed lines), temperature (dotted line); from ref. [22]. 
cleaning and conditioning, a reactor type was sought that converts olefin-containing gas mixtures without detrimental formation of carbon deposits. It was found that moving the catalyst particles within a fluidised bed reactor allows unsaturated hydrocarbons to be handled. Two main reasons could be identified: The movement of the catalyst particles improves the heat transfer and it allows for internal regeneration of the catalyst.

\subsubsection{Heat Removal Performance}

Moving the catalyst particles inside the reactor improves the heat removal performance twofold: first, laminar boundary layers on the surface of heat exchanger surfaces are continuously disturbed which increases the local heat transfer coefficient; secondly, the heat release by the chemical reactions occurs on the catalyst particles. Moving these throughout the reactor therefore spreads the heat production in axial direction and renders the complete immersed heat exchanger surface available for the heat removal. In consequence, fluidised bed methanation reactors can be operated isothermally at lower temperatures. [24] This allows the use of more active catalysts (no need for high temperature stability) and lowers the tendency towards carbon deposition. Further, this reactor type is a promising candidate for Power-to-Gas applications which are, as discussed above, strongly limited by thermodynamic equilibrium and therefore by heat transfer. ${ }^{[22]}$

\subsubsection{Internal Catalyst Regeneration}

Carbon monoxide and hydrocarbons dissociate on the surface of nickel catalysts leading to single carbon atoms on the catalyst surface as was shown by isotope labelling experiments. ${ }^{[14,17]}$ The rate of carbon deposition is significantly higher for ethyne and ethene than for ethane and methane. If these carbon atoms cannot react away fast enough, they could block sites for hydrogen adsorption and form nickel carbides or polymerise even at relatively low temperatures, which finally leads to slow catalyst deactivation. ${ }^{[15,16,18]}$ Moving the catalyst particles through the fluidised-bed reactor transports them into the upper regions with no or very low concentration of carbon-depositing reactant species while the conversion of carbon atoms with hydrogen and/or steam still can take place. This way, the fluidisation of the catalyst particles helps to limit the carbon atom hold-up on the catalyst surface and therefore to significantly slow down irreversible carbon deposition. Moreover, unsaturated olefins such as ethylene can be hydrogenated to ethane which is a desired compound in SNG due to its high volumetric heating value.[25]
There are a few reasons why fluidised-bed reactors are not applied frequently for catalytic processes. Besides the limited experience with this reactor type in many research groups and companies, the two main challenges are its hydrodynamic complexity and the need for mechanically stable catalyst material to limit catalyst loss by attrition. While there are commercially available catalysts with sufficient stability, research on attrition phenomena ${ }^{[26]}$ and on developing even more stable catalyst supports $^{[27]}$ is on-going.

The complexity in the flow pattern of fluidised beds is caused by the rising voids in fluidised beds, also referred to as bubbles. While a certain gas velocity is necessary to lift the catalyst particles (which is the on-set of fluidisation), the excess gas at even higher gas flows rises as nearly catalyst-free 'bubbles' through the gas-particle mixture, which behaves in many aspects similar to liquids. The rising bubbles help to improve the heat transfer and to move the catalyst particles, but can cause undesired reactant break-through when they rise too fast compared to the mass transfer. As a result, reliable design of fluidised-bed reactors needs detailed knowledge on the size and rise velocity of the bubbles, which are strongly influenced by the immersed heat exchanger tubes. In the last years, important efforts including method development have been focused on determination of bubble properties in catalytic fluidised-bed reactors by pressure fluctuation measurements, optical probes and X-ray tomography. ${ }^{[28-33]}$ Further, rules for reliable scaleup of bubbling fluidised beds with vertical internals have been derived. ${ }^{[3,35]}$ The knowledge on bubble size distributions and bubble rise velocity distribution can be used to derive hydrodynamic correlations to describe flow patterns in computer models. Together with experimentally determined kinetics, ${ }^{[36]}$ it was possible to setup a detailed reactor model ${ }^{[37]}$ describing the physical-chemical phenomena which can be used to simulate the reactor performance for up-scaled reactors and varying gas compositions for the different process chains (wood-to-SNG, Power-to-Gas with biogas etc.). Further, such detailed ratebased models can be used for detailed process chain analyses. ${ }^{[38,39]}$

In parallel to these more lab-based activities, long-duration tests of gas cleaning and fluidised bed methanation were conducted using a slip stream of the commercial wood DFB gasifier in Güssing/Austria. ${ }^{[40]}$ These tests showed good performance for more than $1000 \mathrm{~h}$ and were the basis for up-scaling the process chain. Within the EU project BioSNG, a $1 \mathrm{MW}_{\mathrm{SNG}}$ pilot plant (Fig. 4) was erected, commissioned and successfully operated, which reached a chemical efficiency from wood to methane of $61 \%$ while producing SNG in high quality. ${ }^{[1]}$ Ongoing research focuses on broadening the know-how basis for higher oper-

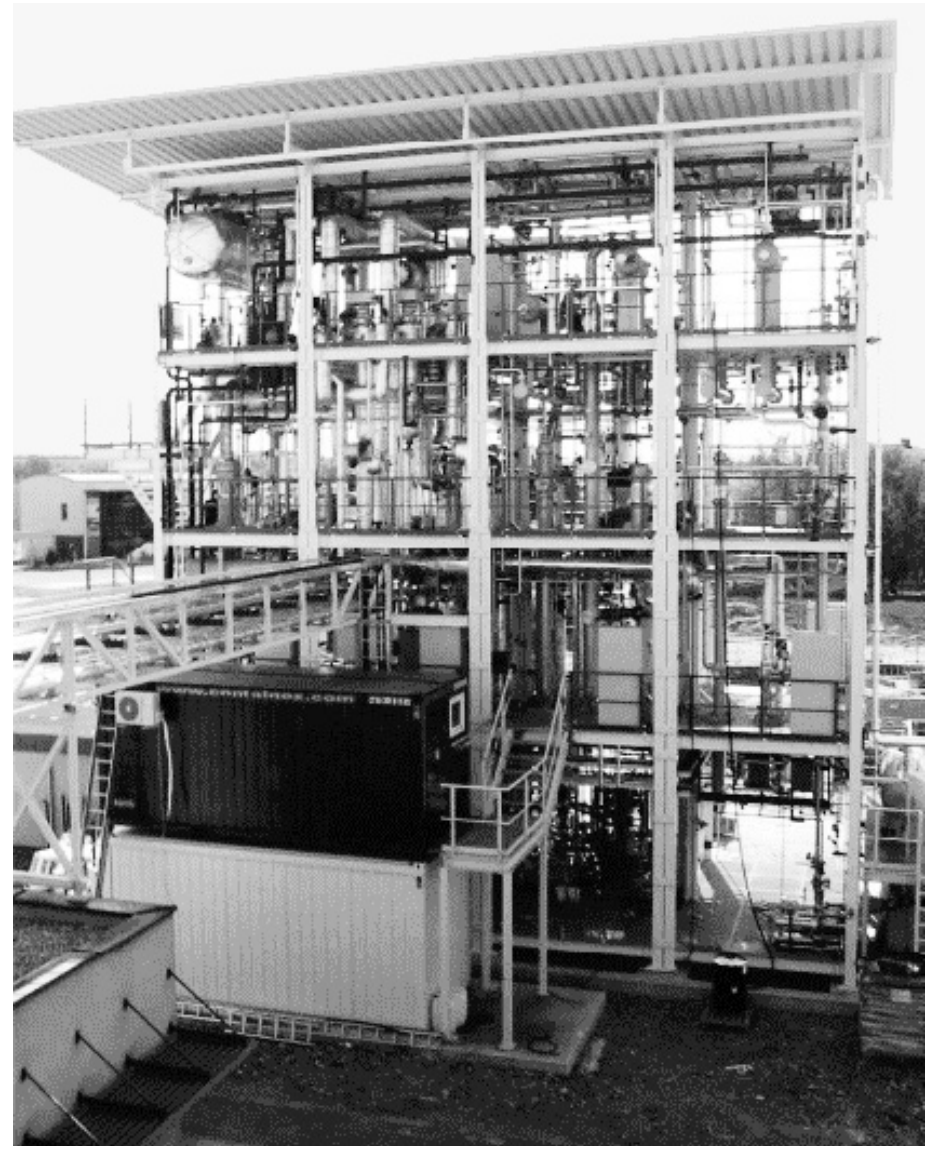

Fig. 4. The $1 \mathrm{MW}_{\mathrm{SNG}}$ process development unit (PDU) in Güssing, Austria, converting wood-derived producer gas to SNG. 
ation pressures and for (dynamic) Powerto-Gas applications using $\mathrm{CO}_{2}$, biogas and even producer gas from wood gasification as carbon source.

\subsection{Metal Monolith Reactors (KIT-EBI)}

Besides by fluidisation of the catalyst particles, the heat of exothermic reactions can be dispersed in a catalytic reactor by introduction of highly thermally conducting structures. ${ }^{[41]}$ The Engler-Bunte-Institut (Karlsruhe Institute of Technology) developed a methanation reactor which realises the concept by coating the nickel catalyst on metal monoliths which help to transport the heat radially and axially. ${ }^{[42]}$ This way, hot spots can be dampened significantly. The reactor development is supported by CFD simulations and tests within a container-based plant. The targeted application is the conversion of wood gasification-derived producer gas with hydrogen from electrolysis within a Power-to-Gas process. As the catalyst in the monolith is fixated, such a reactor is most probably vulnerable to carbon deposition in presence of olefins. For the targeted process chain, an olefin-free producer gas is therefore necessary, which can be delivered for instance by the so-called 'Woodroll'-gasifier. The absence of olefins in the producer gas of this strongly heat integrated high temperature gasifier implies in turn also a low methane content (around 1\%) and a lower overall process chain efficiency. So far, limited experimental information to this concept and only one simulation study is available. ${ }^{[43]}$

\section{Conclusions}

Production of synthetic natural gas from biomass is an important step to decouple the use of bioenergy from the biomass production with respect to both time and place. While anaerobic digestion of wet biomass is a state-of-the art process, wood gasification and methanation of the cleaned producer gas just goes beyond pilot scale. Power-to-Gas applications using biomass (biogas or wood gasification-derived producer gas) as carbon oxide source are under development. The different reactor technologies for catalytic methanation have their specific advantages depending on the application; especially when low temperature gasification is applied, fluidised-bed methanation allows a significant simplification of the gas cleaning and conditioning section. For all process chains, reactor development is supported by modelling/simulation and extended field testing in the 10-25 kW range, followed by operation of pilot scale plants in the 100 to $1000 \mathrm{~kW}$ scale.

Received: August 17, 2015

[1] J. Kopyscinski , T. J. Schildhauer, S. M. A. Biollaz SMA, Fuel. 2010, 89, 1763.

[2] A. Kruse, F. Vogel, J. van Bennekom, R. Venderbosch, in 'Handbook Biomass Gasification', 2nd Edition, Ed. H. A. M. Knoef, btg Biomass Technology Group, 2012.

[3] Göteborg Energi Press release, 18.12.2014. http://gobigas.goteborgenergi.se/En/News

[4] F. P. Nagel, T. J. Schildhauer, S. Biollaz, Int. J. Hydrogen Energ. 2009, 34, 6809.

[5] F. P. Nagel, S. Ghosh, C. Pitta, T. J. Schildhauer, S. Biollaz, Biomass Bioenerg. 2011, 35, 354.

[6] A. Kambolis, T. Schildhauer, O. Kröcher, Chimia 2015, 69, 608.

[7] M. V. Twigg, 'Catalyst Handbook', Wolfe, London, 1989.

[8] M. D. Kaufman Rechulski, T. J. Schildhauer, S. M. A. Biollaz, C. Ludwig, Fuel 2014, 128, 330.

[9] M. D. Kaufman Rechulski, PhD Thesis EPF Lausanne No. 5484, 2012.

[10] L. P. L. M. Rabou, L. Bos, Appl. Catal. B 2012, $111,456$.

[11] E. H. Rönkkönen, PhD Thesis Aalto University, 2014.

[12] U. Rhyner, PhD Thesis ETH Zürich No. 21102 , 2013.

[13] F. Lind, N. Berguerand, M. Seemann, H. Thunman, Energ. Fuel. 2013, 27, 997.

[14] J. Zarfl, T. J. Schildhauer, J. Wambach, A Wokaun, 'Conversion of ethane / ethylene / acetylene under methanation conditions'. Submitted to Appl. Catal. A $\mathbf{2 0 1 5}$.

[15] C. H. Bartholomew, Catal. Rev.-Sci. Eng. 1982, 24, 67.

[16] J. G. McCarty, H. Wise, J Catal. 1979, 57, 406

[17] J. Zarfl, PhD Thesis ETH Zürich No. 22183, 2015.

[18] I. Czekaj, F. Loviat, F. Raimondi, J. Wambach, S. Biollaz, A. Wokaun, Appl. Catal. A 2007, 329, 68

[19] R. Rauch, J. Hrbek, 'Country Report Austria', IEA Bioenergy Task33 Meeting, Istanbul, 2012.

[20] H. Thunman, Presentation IEA workshop, 2013.

[21] G. Aranda Almansa, L. P. L. M. Rabou, C. M. van der Meijden, A. van der Drift, 'ECN System for MEthanation (ESME)', 23 $3^{\text {rd }}$ European Biomass Conference and Exhibition, Vienna, 2015.

[22] T. J. Schildhauer, J. Settino, S. 1. Teske, 'Modelling study of fixed bed reactors with dumped catalyst particles and structured catalyst supports for $\mathrm{CO}_{2}$ methanation in Power-to-Gas applications', Manuscript submitted, 2015.
[23] D. Schlereth, O. Hinrichsen, Chem. Eng. Res. Des. 2014, 92, 702 .

[24] J. Kopyscinski, T. J. Schildhauer, S. M. A. Biollaz, Chem. Eng. Sci. 2011, 66, 924.

[25] J. Kopyscinski, M. C. Seemann, R. Moergeli, S. M. A. Biollaz, T. J. Schildhauer, Appl. Catal. A 2013, 462, 150.

[26] S. Maurer, S. Rodríguez Durán, M. Künstle, S. M. A. Biollaz, 'Influence of interparticle forces on attrition and elutriation in bubbling fluidized beds', Manuscript submitted, 2015

[27] N. van Garderen, F. J. Clemens, M. Mezzomo, Appl. Clay Sci. 2011, 52,115.

[28] M. Rüdisüli, T. J. Schildhauer, S. M. A. Biollaz, J. R. van Ommen, Ind. Eng. Chem. Res. 2012, $51,4748$.

[29] M. Rüdisüli, T. J. Schildhauer, S. M. A. Biollaz, J. R. van Ommen, Chem. Eng. Sci. 2012, 74, 266.

[30] M. Rüdisüli, T. J. Schildhauer, S. M. A. Biollaz, J. R. van Ommen, Int. J. Multiphas. Flow. 2012, $41,56$.

[31] S. Maurer, E. C. Wagner, T. J. Schildhauer, J. R. van Ommen, S. M. A. Biollaz, R. F. Mudde, Int. J. Multiphas. Flow. 2015, 74, 143.

[32] S. Maurer, E. C. Wagner, J. R. van Ommen, T. J. Schildhauer, S. L. Teske, S. M. A. Biollaz, A. Wokaun, R. F. Mudde, Int. J. Multiphas. Flow. 2015, 75, 237.

[33] S. Maurer, E. C. Wagner, T. J. Schildhauer, J. R. van Ommen, S. M. A. Biollaz, R. F. Mudde, Int. J. Multiphas. Flow. 2015, 74, 118.

[34] M. Rüdisüli, T. J. Schildhauer, S. M. A. Biollaz, J. R. van Ommen, Chem. Eng. J. 2012, 197, 435.

[35] S. Maurer, T. J. Schildhauer, J. R. van Ommen, S. M. A. Biollaz, A. Wokaun, Chem. Eng. J. 2014, 252, 131

[36] J. Kopyscinski, T. J. Schildhauer, F. Vogel, S. M. A. Biollaz, A. Wokaun, J. Catal. 2010, 271, 262.

[37] J. Kopyscinski, T. J. Schildhauer, S. M. A. Biollaz, Chem. Eng. Sci. 2011, 66, 1612.

[38] S. L. Teske, I. Couckuyt, T. J. Schildhauer, S. M. A. Biollaz, F. Maréchal, 'Integrating ratebased models into multi-objective optimisation of process designs using surrogate models', Proceedings of the 26th International Conference on Efficiency, Cost, Optimization, Simulation and Environmental Impact of Energy System, 2013.

[39] S. L. Teske, PhD Thesis EPF Lausanne, 2014.

[40] M. C. Seemann, T. J. Schildhauer, S. M. A. Biollaz, Ind. Eng. Chem. Res. 2010, 49, 7034

[41] E. Tronconi, G. Groppi, T. Boger, A. Heibel, Chem. Eng. Sci. 2004, 59, 4941.

[42] S. Bajohr, D, Schollenberger, M. Götz, 'Methanation with Honeycomb Catalysts', 2nd Nuremberg Workshop Methanation and Second Generation Fuels, 2014.

[43] M. Sudiro, A. Bertucco, G. Groppi, E. Tronconi, 'Simulation of a structured catalytic reactor for exothermic methanation reactions producing synthetic natural gas', in 'Computer Aided Chemical Engineering', Eds. S. Pierucci, G. B. Ferraris, Elsevier, Amsterdam, 2010, pp 691 